\title{
El Moderno Prometeo: El Director Escolar como Líder Mediador para la Justicia Social y el Desarrollo Sostenible
}

\section{The Modern Prometheus: The School Principal as a Mediator Leader for Social Justice and Sustainable Development}

\author{
Maricela Guzmán Cáceres ${ }^{1 *}$ \\ Leonardo Oliver Ortiz Flores ${ }^{2}$ \\ ${ }^{1}$ Universidad Autónoma de Coahuila, México \\ ${ }^{2}$ Organización de las Naciones Unidas para la Educación, la Ciencia y la Cultura, México
}

\begin{abstract}
En la presente investigación nos proponemos problematizar la caracterización del liderazgo directivo en el entorno escolar a partir de los aportes teóricos de la justicia social, a la cual definimos como un espectro amplio con tres principales aristas en torno a la construcción de la noción del bien y los medios para alcanzarla: la justicia como equidad de Rawls, el enfoque de capacidades de Sen y la justicia social crítica de Pereira. A su vez, nos proponemos identificar cómo estas aristas operan como un marco axiológico que orienta los Objetivos de Desarrollo Sostenible de la Agenda 2030 y a su vez, cómo dichos objetivos contribuyen a delimitar la serie indeterminada de capacidades que las doctrinas morales comprehensivas persiguen, en un marco de libertad sustantiva. A partir de esta discusión teórica abordamos el papel del director como un líder consciente de la mediación que ejerce entre el ámbito escolar y social capaz de trastocar las injusticias, desde un horizonte ético que remite al "agente de justicia” de Pereira. Ante el reto que plantea esta tarea retomamos la figura prometeica en su carácter trágico-heroico, a fin de alertar sobre la estructura y las estrategias de respaldo necesarias en el impulso de toda labor transformadora. En ese sentido, se argumenta que la Educación para el Desarrollo Sostenible (EDS) ofrece un marco de referencia a nivel cognitivo, socioemocional y conductual para el abordaje de problemáticas transversales que inciden en el aula desde un horizonte de justicia social y liderazgo sostenible.
\end{abstract}

Descriptores: Justicia social; Liderazgo; Mediación; Sociología de la educación; Sostenibilidad.

In the present investigation, we propose to problematize the characterization of the directive leadership in the school surroundings from the theoretical contributions of social justice, which we define as a broad spectrum with three main edges around the construction of the notion of the good and the means to achieve it: justice as equity by Rawls, the capabilities approach of Sen and the critical social justice of Pereira. At the same time, we propose to identify how these edges operate as an axiological framework that guides the Sustainable Development Goals of the 2030 Agenda and, in turn, how these objectives contribute to delimit the indeterminate series of capacities pursued by comprehensive moral doctrines, in a framework of substantive freedom. From this theoretical discussion, we approach the role of the director as a conscious leader of the mediation that exerts between the school and social

*Contacto: mari68mx@yahoo.com.mx

ISSN: 2254-3139

www.rinace.net/riejs/

revistas.uam.es/riejs
Recibido: $\quad 15$ de diciembre 2018

$1^{\text {a }}$ Evaluación: 20 de enero 2019

$2^{\text {a }}$ Evaluación: 11 de febrero 2019

Aceptado: 17 de febrero 2019 
environment capable of upsetting injustices, from an ethical horizon that refers to the "agent of justice" of Pereira. In view of the challenge posed by this task, we return to the Promethean figure in its tragic-heroic character, in order to warn about the structure and the necessary support strategies in the impulse of all transformative work. In this sense, it is argued that Education for Sustainable Development (EDS) offers a frame of reference at a cognitive, socio-emotional and behavioral level to address cross-cutting issues that affect the classroom from a social justice and sustainable leadership perspective.

Keywords: Social justice; Leadership; Mediation; Sociology of education; Sustainability.

\section{Introducción}

La conjunción de esfuerzos entre diversos actores a nivel local y global para alcanzar los 17 Objetivos de Desarrollo Sostenible (ODS) y las 169 metas enmarcadas en la Agenda 2030 (2016-2030), signada en septiembre de 2015 entre los 193 países miembros de la Organización de las Naciones Unidas (Bórquez y Lopicich, 2017; UNESCO, 2017), refleja un creciente interés común por abordar una serie de problemáticas de opresión, desigualdad y exclusión desde un enfoque sistémico e interrelacionado, que busca concretar el efectivo ejercicio de los derechos humanos. Esto nos plantea una serie de interrogantes: ¿qué implica un desarrollo sostenible?, ¿qué dimensiones se ven afectadas?, ¿qué relación hay entre sostenibilidad y justicia social?, ¿qué papel pueden jugar los líderes escolares como agentes de cambio?

A partir de estas preguntas partimos de la hipótesis de que los oDs pueden fungir como un itinerario delimitado que contribuye a esbozar la serie de capacidades que las doctrinas morales comprehensivas han propuesto para concretar la búsqueda del bien y la justicia en un marco de libertad sustantiva entre intereses diversos, desde un consenso elaborado reflexivamente. Enseguida, nos proponemos mostrar la interrelación entre el desarrollo sostenible y la justicia social, a nivel teórico y programático, y destacar el rol de los "agentes de justicia social" de Pereira (2016), que en el caso de las aulas se expresan en el papel de "líder activista" (Turhana, 2010), que los directores escolares asumen como mediadores para armonizar las demandas de redistribución y reconocimiento, desde una perspectiva de liderazgo sostenible (Hargreaves y Fink, 2008). Siguiendo este planteamiento, se argumenta cómo la Educación para el Desarrollo Sostenible (EDS) puede contribuir con una serie de estrategias que permitan identificar y abordar problemáticas transversales que inciden en el entorno escolar desde un enfoque de justicia social.

El enfoque metodológico seguido en este trabajo fue de carácter hermenéutico, ya que vincula el campo estrictamente teórico sobre la justicia social con el teórico-empírico del liderazgo escolar para la justicia social. Este enfoque obedeció a la importancia que tiene la justicia social como marco teórico para un liderazgo moralmente comprometido en las escuelas y el papel que juegan las políticas de redistribución y reconocimiento en la concreción de dicho objetivo (Bolívar, 2012; Bogotch y Reyes-Guerra, 2014; Brown, 2014; Heredia y Martínez, 2014; Murillo, et. al., 2014; Murillo y Hernández-Castilla, 2011; Santamaría y Stuardo, 2018). Sin embargo, es necesario comprender la interrelación entre ambas y en particular a las demandas de reconocimiento no como un "paradigma emergente" que "va más allá de la esfera económica" (Bolívar, 2012, p. 20) -en relación a las demandas redistributivas- sino más bien como dos caras de un mismo proceso que se interrelacionan y que apuntan a concretar la justicia social en dichas esferas sin menoscabo de alguna de las dos (Fraser, 2008). Un ejemplo de esta interrelación o bidimensionalidad 
de la justicia se expresa en la articulación trazada en las metas de desarrollo sostenible. Así, el ODS 5, la igualdad de género, no se contrapone al 8, el trabajo decente con crecimiento económico, sino que se complementan. La posibilidad de articular diversas problemáticas interrelacionadas a partir de la reflexión en el espacio escolar que la EDS puede suscitar es abordada en función del "agente de justicia" (Pereira, 2016) como mediador, junto con otras categorías clave, como el liderazgo distribuido, la capacidad escolar (DeMatthews, 2014) y el líder activista (Turhana, 2010).

\section{El espectro de la justicia social: Entre los valores políticos y las doctrinas morales comprehensivas}

En la caracterización de la justicia social como un espectro delimitado por las tres aristas antes aludidas, nos proponemos abordar a los paradigmas de la justicia social, no como dos corrientes antagónicas ${ }^{1}$, sino más bien como un continuum de referentes axiológicos para el ejercicio de la justicia social en el cual se encuentran entrelazados principios clave de las doctrinas involucradas, es decir, tanto la inviolabilidad del individuo en tanto unidad mínima de organización del liberalismo, como la reciprocidad en la determinación de derechos y obligaciones, del materialismo histórico.

Antes de abordar el espectro de la justicia social en sus tres aristas, conviene exponer los dos polos opuestos desde los que se teoriza la justicia social según un enfoque que parte del antagonismo entre liberalismo y materialismo dialéctico. Dentro de las corrientes liberales encontramos dos variantes, la ortodoxa y la igualitarista. La primera de ellas parte del principio de la división entre el Estado y el mercado como mediadores de las transacciones entre los ciudadanos. La intervención del Estado se limita a garantizar el derecho a la vida y a la libertad y en segunda instancia a la propiedad privada. El mercado a su vez es el mediador imparcial de las relaciones y transacciones entre individuos libres. Dichas transacciones se formalizan y perfeccionan en contratos, que el Estado debe proteger. El eje de justicia se enmarca en que dichas transacciones entre individuos con capacidades iguales sean justas (Giraldo-Piedrahita, 2015).

Por su parte, la corriente igualitarista o redistributiva, fundamenta el ejercicio de los derechos en la noción de sujeto moral de Kant, que implica la autodeterminación en el ejercicio de las libertades y la dignidad de la persona. El sujeto moral es una categoría universal que sustenta dicha autodeterminación en el marco del Estado-nación (GiraldoPiedrahita, 2015). Esta corriente ha sido desarrollada profusamente en dos principales sublíneas: la justicia como equidad de Rawls (1999) y el enfoque de capacidades de Sen (2009).

De acuerdo con Yilmaz (2016) el planteamiento de Rawls puede ubicarse como una crítica al utilitarismo, misma que realizó a partir del principio liberal de la inviolabilidad del individuo por encima del colectivo. Derivado de esta crítica, se funda su noción de redistribución: para sustentar la justicia como equidad a cada individuo se deben distribuir ciertos bienes mínimos o primarios (poderes y prerrogativas de autoridad, de ingresos y bienestar) que le permitan perseguir sus finalidades, sin establecer a priori cuál debería

${ }^{1}$ A saber, la liberal radical u ortodoxa y la liberal igualitarista o redistributiva, frente a la marxista o igualitarista (GiraldoPiedrahita, 2015; Peñaranda, 2015), que se ubicarían desde un referente liberal frente a otro materialista, respectivamente. 
ser el último fin para emplear su autonomía y sin obstaculizarle tal búsqueda (libertad negativa), razón por la que su teoría se funda en el valor político de la justicia más que en una doctrina moral comprehensiva de la misma (Yilmaz, 2016).

Por su parte, la teoría de la elección social de Sen y su enfoque de capacidades es una reacción a la excesiva abstracción de la teoría política de justicia social de Rawls (Yilmaz, 2016). Para Sen, la lógica de justicia como equidad centrada en la redistribución de recursos y basada en una plataforma institucional, no permite que los diferentes sujetos puedan convertir esos recursos en medios para alcanzar libremente el bienestar, según sus capacidades. El objetivo del enfoque de capacidades es desarrollar una medida más precisa del bienestar individual en función de un parámetro de libertad sustantiva, disponible a toda persona, razón por la que se le identifica como una doctrina moral comprehensiva. Nussbaum (2012) ha contribuido con esta línea al proponer una serie mínima de capacidades, aunque advierte que tal conjunto siempre será inacabado y abierto (Yilmaz, 2016).

En el polo opuesto de estas variantes de liberalismo, se ubicaría la corriente materialista, o como Giraldo-Piedrahita (2015) la llama, "marxista/igualitarista" de la justicia social. Esta corriente parte del principio materialista de las relaciones de producción como mediadoras del proceso histórico y de la apropiación injusta de los mismos por parte de una clase o grupo de poder, lo que deriva en una desigualdad estructural. El agente de este principio es el sujeto histórico, condicionado por sus determinaciones y a la vez con el potencial de transformarlas, y el sujeto político, capaz de incidir en las relaciones de poder mediante prácticas emancipadoras (Giraldo-Piedrahita, 2015). A diferencia de la corriente liberal-igualitaria que dio lugar a dos grandes líneas, la justicia social se asocia al corpus general del materialismo y a su noción subyacente de la lucha de clases.

\subsection{Concepciones convergentes de justicia}

Tanto la justicia como equidad sustentada en bienes mínimos de Rawls, como la habilitación en un conjunto de capacidades de Sen, son teorías basadas en la libertad de elección que legitiman la búsqueda individual de la concepción del bien. De ahí que, sin dejar de pertenecer al espectro de teorías liberales, marcan una crítica a la visión más ortodoxa que sostiene el utilitarismo.

Al mismo tiempo, incorporan elementos del socialismo como teoría política, con la igualdad en el caso de Rawls y la emancipación en el caso de Sen (Yilmaz, 2016). Por lo tanto, se les puede ubicar como elaboraciones teóricas impulsadas en respuesta a las doctrinas que cuestionan la preeminencia del individuo como núcleo del contrato social que legitima la propiedad privada, al enfatizar el margen de autonomía y libertad de elección que cada individuo tiene en la construcción de una sociedad justa.

Por otro lado, como una meta-crítica de ambas doctrinas políticas, la justicia social crítica (Pereira, 2016) aparece como una elaboración teórica que parte de las insuficiencias del liberalismo como doctrina para llevar a sus últimas consecuencias los postulados de justicia social, en particular, el enfoque de capacidades de Sen. Esta teoría parte del debate abierto por Sen en torno a la medición precisa de las condiciones que habilitan a un individuo para llevar a cabo su plan de vida. Según Pereira, los principios básicos de la justicia social crítica: el reconocimiento, la intersubjetividad y la alta sensibilidad a la vulnerabilidad, tienen el potencial de ampliar los horizontes abiertos por el enfoque de capacidades. En conjunto, estos tres principios configuran las llamadas "autorrelaciones 
prácticas del yo”, que el autor recupera de Honneth (1997) y que se componen de: “autoconfianza, auto-respeto y autoestima” (Pereira, 2016, p. 90). Esta condición de reconocimiento mutuo se establece como el parámetro que le otorga significación a las metas que cada quien se fija, las cuales de otra manera serían indeterminadas y vacías de sentido.

La afinidad teórica entre el enfoque de capacidades y la justicia social crítica radica en que comparten un planteamiento común como doctrinas morales comprehensivas, es decir, que se fundan en nociones históricamente situadas de la justicia y que desplazan la determinación individual de la búsqueda del bien hacia una concepción relacional y por lo tanto colectiva. Es precisamente esta articulación teórica la que marca su distanciamiento con respecto al liberalismo, el cual busca conservar la individualidad por encima de toda asimilación colectiva. Al mismo tiempo, esta asimilación colectiva marca sus límites con el utilitarismo ya que ella no implica una subordinación a un ente hegemónico, sino una constitución relacional de las individualidades.

Como resultado de esta afinidad, una categoría clave que emerge es el "agente de justicia social" (Pereira, 2016, p. 106) el cual es un papel que asumirían los ciudadanos dentro de un contrato social que se caracteriza por ser relacional en la constitución de la propia autoestima y el auto respeto. Este contrato se basa en el reconocimiento recíproco y se establece como una idea fuerza, que orienta la consecución del bien común. Si bien De Vita (2014) advierte que la justicia social crítica enfrenta el reto de aspirar a consensuar un paradigma de lo justo moralmente más demandante que el de la libertad negativa, es un aporte que se sitúa como mediación entre los bienes primarios de Rawls enfocados en la provisión de recursos, y la búsqueda de una métrica más precisa para determinarlos, de Sen. A continuación, interesa destacar la articulación entre las doctrinas morales comprehensivas con el discurso de la sostenibilidad y el papel mediador de los líderes escolares en la formación de "ciudadanos de sostenibilidad” (UNESCO, 2017, p. 10).

\subsection{Del desarrollo sostenible a la sostenibilidad del cambio en las escuelas.}

El discurso de la sostenibilidad, entendido como la necesidad de compaginar el desarrollo social, económico y ambiental sin menoscabo de las necesidades de las generaciones futuras, se hizo presente desde el Informe "Nuestro futuro común” de 1987 y se afianzó con la Declaración de Río sobre el Medio Ambiente y el Desarrollo de 1992. Más tarde, con la Cumbre del Milenio en 2000 y la firma de los Objetivos de Desarrollo del Milenio (ODM), estas tres dimensiones aparecieron como un programa común. Con los ODM se perfilaba una redistribución de la riqueza en las dinámicas Norte-Sur (Bórquez y Lopicich, $2017)$.

Como señala Murga-Menoyo (2018) la firma de los oDs representa una transición en la sostenibilidad como se venía articulando, ya que se enfatiza la importancia de considerar las implicaciones de un desarrollo que afecta a los actores involucrados, a la vez que se destacan los efectos que, el crecimiento de los países más industrializados, generan sobre aquéllos en vías de desarrollo y en general sobre la sostenibilidad del planeta como causa común. Llama la atención que en el discurso de los ODS todas las naciones son concebidas como “en desarrollo” hacia las metas de sostenibilidad (UNESCO, 2017, p. 6).

Esta reorientación en particular ha girado sobre las reflexiones que ha abierto la necesidad de compaginar la sostenibilidad ecológica con la económica y la social, ya que no necesariamente un incremento en los indicadores de la sostenibilidad ecológica y los 
índices de crecimiento económico implican una reducción en la pobreza y la desigualdad. Esta paradoja es posible ya que perfectamente puede coexistir una política ambiental alternativa, como la agroecología, con la explotación laboral y el trabajo infantil (Foladori, 2006) por lo que un desarrollo así no puede ser sostenible.

El diseño de los ODS recoge estas reflexiones en torno a la necesidad de armonizar esas tres dimensiones del desarrollo. Esta es una meta que se propone a través de la articulación de diversos actores, a nivel local y global, en la consecución de 17 metas interrelacionadas entre sí y que portan una noción de lo justo que se asume como deseable y consensual y, por lo tanto, construida reflexivamente, en términos de la justicia social crítica, e históricamente situada, en términos de las doctrinas morales comprehensivas.

Las afinidades entre el enfoque de capacidades como doctrina moral comprehensiva y el discurso de la sostenibilidad encuentran un antecedente desde 1990, cuando el Programa de las Naciones Unidas para el Desarrollo (PNUD) incorporó la noción de "desarrollo humano sostenible", pues ello implicaba poner atención al fomento de las capacidades para la satisfacción de las necesidades (Vergara y Ortiz, 2016). Esta relación se busca establecer en términos de una libertad sustantiva, la cual se puede plantear desde la colaboración de diversos actores que son convocados en el marco de la Agenda 2030. Este objetivo ya aparecía delineado en estos términos desde el Informe 2004 del PNUD, en el cual se señalaba la relación directamente proporcional entre el aumento de las libertades humanas y las capacidades personales para el logro de una vida plena (Sanz-Ponce y SerranoSarmiento, 2016).

La Educación para el Desarrollo Sostenible (EDS)2, busca aportar en ese sentido, fomentando la capacidad de comprensión, empatía y acción para la transformación en los "ciudadanos de sostenibilidad" que Wals $(2015$, p. 13) concibe como una ciudadanía crítica, alfabetizada en las competencias de sostenibilidad sin por ello caer en una lógica prescriptiva que inhiba el compromiso activo. Si bien la EDS busca formar ciudadanos que comprenden la complejidad de su entorno y que sean capaces de colaborar y actuar para fomentar "la integridad ambiental, la viabilidad económica y una sociedad justa para generaciones presentes y futuras" (UNESCO, 2017, p. 7), Wals (2015) ha advertido sobre su tendencia a volverse prescriptiva y mecanicista. No obstante, el desgranamiento de la EDS en los objetivos de aprendizaje a nivel cognitivo, socioemocional y conductual es capaz de suscitar un pensamiento complejo, que permite interrelacionar las dimensiones de los 17 ODS.

La integración de esta agenda programática para el desarrollo sostenible desde los objetivos de aprendizaje de la EDS involucra a los educadores y a las escuelas en un plano central en la consecución de dichos objetivos. Pero al mismo tiempo, esta agenda los coloca en una posición de muy alta responsabilidad y de altas expectativas. Por lo tanto, no basta con incorporar la Educación para el Desarrollo Sostenible en las comunidades escolares sino, además, y primordialmente, es prioritario que la misma organización escolar y sus actores incorporen la lógica de sostenibilidad en sus dinámicas internas, como lo han advertido Hargreaves y Fink (2008).

\footnotetext{
${ }^{2}$ Concebida desde 1992, la EDS adquirió mayor sistematicidad en 2002 con la Resolución 57/254 de la Asamblea General de Naciones Unidas, la cual dio pauta para el Decenio de la Educación para el Desarrollo Sostenible (DEDS) 2005-2014 (Unesco, 2017).
} 
Las presiones y rendimientos que se exige a las escuelas suelen abordarse mediante la imposición de procesos estandarizados que, a la larga, terminan siendo insostenibles y arrojan a los líderes escolares a una dinámica que, a semejanza de la figura prometeica, es heroica pero efímera. Esto también aplica a la implementación de la EDS, pues por más loables que puedan ser las metas que dicho enfoque persigue, si la escuela no cuenta con una estructura que le permita incorporarlas y desarrollarlas, el intento de aplicarla puede llegar a ser contraproducente.

Por lo tanto, la mejora educativa requiere transitar del paradigma de la estandarización al de la diversidad y la sostenibilidad. Como lo sugieren Hargreaves y Fink (2008) este nuevo paradigma requiere a su vez de un liderazgo sostenible, que no dependa de una sola figura protagónica, que sea capaz de mantener sus objetivos a largo plazo y que al impulsar cambios que prioricen el perfeccionamiento de los procesos por sobre la rapidez de los resultados logre evitar el "síndrome del cambio repetitivo" (p. 23).

Entre las siete propiedades clave que estos autores atribuyen al liderazgo sostenible la justicia es quizá la piedra angular de todas. Se puede lograr una sostenibilidad hasta cierto punto eficiente, si se ejerce la profundidad, la distribución o la duración, pero sin un horizonte de justicia tales atribuciones terminan minadas si no se construyen consensos reflexivos y dinámicas equitativas. Es por esto que la sostenibilidad es "inherentemente moral" (Hargreaves y Fink, 2008, p. 28), a diferencia del pensamiento sistémico, proclive a volverse instrumental, y a la vez es socialmente justa, pues se plantea metas desde una lógica reflexiva, a manera de la justicia social crítica. Como señalan Hargreaves y Fink (2008), "la sostenibilidad es una inextricable cuestión de justicia social" (p. 127).

A partir de este panorama nos proponemos retomar la propuesta de justicia social crítica de Pereira para aportar al perfil del director como líder desde una perspectiva sostenible. Asimismo, buscamos identificar en qué medida la Educación para el Desarrollo Sostenible (EDS), que busca fomentar competencias transversales de sostenibilidad, pueden ser una guía para el líder escolar consciente de su papel para construir entornos más justos en contextos retadores.

\section{El “agente de justicia” en las escuelas: El moderno Prometeo}

La importancia que juega dentro de la organización escolar, el asumir un liderazgo orientado a la justicia social, radica en que habilita a los educadores a enfrentar los retos éticos que suceden en los entornos escolares, mismos que involucran al colectivo docente y la comunidad escolar. Asumir esta postura los sitúa ante un ejercicio de permanente vigilancia epistémica con respecto a su práctica y en relación a los fines establecidos en el currículum. Esta vigilancia se ejerce a través de la reflexión-acción desde el paradigma de la Investigación Acción Participativa (IAP), ya que al reconocer e incorporar los saberes y experiencias de los miembros que integran la comunidad escolar, el líder hace de mediador entre los desiguales contextos de sus estudiantes y las metas que se plantea alcanzar para todos; haciéndolos partícipes del análisis y abordaje de su situación. Esto le exige mantener constantemente altas expectativas sobre cada uno de sus alumnos, deslegitimando así el discurso que relega a priori, a los estudiantes con antecedentes socioeconómicos y socioculturales deficitarios, a seguir una trayectoria escolar igualmente deficitaria (González, 2014; Rauber, 2012). 
Una práctica que contribuye a estos fines es el liderazgo distribuido (DeMatthews, 2014), en el cual se propicia la participación equitativa de los miembros de la comunidad escolar y se procura e incentiva el logro de sus metas. Junto con la IAP, esta práctica de liderazgo se ubica en sintonía con la construcción relacional de la individualidad en función de las autorrelaciones del yo, que propone la justicia social crítica. Según el planteamiento de Pereira (2016, p. 106), todos los individuos son en potencia, un "agente de justicia", en tanto que construyen sus nociones del bien desde una lógica relacional.

Asimismo, el agente de Pereira guarda correspondencia con el líder "educativo-activista" que Turhana (2010, p. 1360) elabora, en relación al papel que juega el director en la escuela. Este líder-activista se caracteriza por promover la institucionalización de la justicia social en las escuelas, al ser consciente del impacto de dichas acciones en los desequilibrios económicos del entorno social circundante. Este liderazgo es "una intervención deliberada que requiere el uso de la fuerza", de ahí que se defina al liderazgo para la justicia social como una "influencia para asegurar la justicia social en determinada organización" (Turhana, 2010, p. 1359).

Además de esta intervención deliberada, el liderazgo escolar para la justicia social también se caracteriza por su orientación moral, que le otorga al educador un sentido de responsabilidad para promover logros relevantes en igualdad de condiciones, y en particular, para aquellos estudiantes que representan a los sectores socioeconómicamente marginados, culturalmente oprimidos o que enfrentan barreras de acceso e inclusión. Esta responsabilidad moral es lo que lleva a los educadores que ocupan posiciones de liderazgo a cuestionar y contender con las estructuras jerárquicas que tienden a privilegiar a un determinado perfil de estudiante en detrimento de otros, para deconstruirlas y subvertir el orden establecido (Jean Marie, Normore y Brooks, 2009). Encarar esta labor requiere de un liderazgo sostenible y socialmente justo, que no sólo se preocupa por gestionar las labores que llevarán a resultados positivos, sino que considera el impacto que generará entre los miembros de su comunidad (Hargreaves y Fink, 2008).

En ese sentido, la escuela es una institución clave para abordar las injusticias dado que en ella convergen orígenes y estratos sociales, culturales y económicos diversos. Por lo tanto, Turhana (2010) propone que la escuela, como institución, asuma el abordaje de esas desigualdades desde un enfoque de liderazgo ético para la justicia social. Este enfoque involucraría a todos los gestores que toman parte en la organización escolar, pues tienen la capacidad de nivelar las diferencias de origen de sus miembros para llegar, en igualdad de condiciones, a una meta en común. Tal acción deliberada, imbuida de una responsabilidad moral, es la que define al moderno Prometeo de las aulas.

El énfasis en esta responsabilidad moral cobró mayor ímpetu con el tránsito en la década de 1980 de los periodos ideológico, prescriptivo y científico, caracterizados por el énfasis excesivo en el desarrollo de habilidades gerenciales y su postura discriminatoria de la diversidad, al periodo dialéctico, que enfatizó la importancia de que el líder escolar colabore con las familias en contextos de desigualdad y atienda las demandas de su contexto social, cultural, económico y político. (Jean Marie, Normore y Brooks, 2009)

El liderazgo escolar en el periodo dialéctico se orientó más explícitamente hacia el objetivo de construir escuelas justas, lo que implicó pensar cómo los mecanismos curriculares se relacionan con las diferencias étnicas, de género, de orientación sexual, entre otras, para la perpetuación de desigualdades en ciertos sectores. La orientación que el liderazgo para la justicia social asumió en este periodo se nutrió de marcos críticos, como la teoría crítica 
multicultural, la teoría queer y el feminismo postestructural, lo que ya anunciaba la emergencia de las demandas de reconocimiento. Posterior a esta etapa deconstructiva tomó consenso la importancia de transitar a una fase "reconstructiva" (Jean Marie, Normore y Brooks, 2009)

Una aportación estratégica en ese sentido es la de Theoharis (2007), quien ubica a la justicia social bajo el paradigma de la diversidad como constitutiva de los actores escolares, a diferencia del enfoque de inclusión, que parte de una lógica asimétrica y compensatoria. Con base en estos presupuestos, Theoharis (2007) elabora un modelo teórico de liderazgo para la justicia social que articula el plano de la formación y práctica del director con lo que él denomina una "consciencia reflexiva" que le habilita a posicionarse como un agente que se sitúa en una resistencia inmanente a las trabas tanto curriculares como organizacionales que legitiman la segregación educativa. Su modelo plantea tres dimensiones de resistencia: 1) la que el director enarbola, 2) la que enfrenta, y 3) la que desarrolla.

La primera surge como respuesta a la marginación histórica que determinados grupos sociales han padecido y que se manifiesta en áreas como: a) logro educativo; b) mejora de las estructuras escolares y capacidades del personal; y c) reforzamiento de la cultura escolar y comunitaria. La segunda es una reacción a la agenda social del líder y su colectivo y se expresa en tres dimensiones: a) las normas que constriñen el ejercicio de la dirección; b) el personal y la comunidad; y c) la influencia de la autoridad jurisdiccional. Como respuesta, se desarrolla una resistencia que se despliega en dos principales estrategias, las proactivas: y de respaldo. Estas estrategias se fundamentan en el desarrollo de una estructura de comunicación que habilita el trabajo coordinado entre pares ya que ello les permite crear sinergias dentro de su equipo de trabajo, mediante una lógica horizontal que podría enmarcarse dentro del liderazgo distribuido.

A partir de esta organización, el colectivo docente pasa a la tarea de reinventar las normas burocráticas y curriculares para ajustarlas a un horizonte en el que se anulan las lógicas compensatorias como condición previa para ejercer una justicia social que se refleje en el logro de sus estudiantes en igualdad de condiciones, a la vez que generan una cohesión que les permita lidiar con la resistencia a su acción transformadora (Theoharis, 2007). Una práctica similar es la construcción de "capacidad escolar" (DeMatthews, 2014, p. 115), esto es, una estructura de respaldo que previene al colectivo docente de entrar en una dinámica contraproducente de impulsar cambios precipitados o aislados. Dado que en ambos casos se requiere establecer una plataforma coordinada de trabajo como condición previa al abordaje de injusticias que inciden en el entorno escolar, ambas prácticas podrían enmarcarse dentro del liderazgo sostenible, condición previa indispensable para implementar el enfoque de la EDS en las escuelas, como se propone a continuación.

\subsection{El reto de armonizar la redistribución y el reconocimiento: El criterio del líder}

Recuperando el principio de la sostenibilidad del cambio, Hargreaves y Fink (2008) advierten sobre la saturación de iniciativas que se pretenden echar a andar y que a la larga se traslapan, generando caos. Junto a esta saturación, la prisa por ver resultados suele generar un efecto rebote, en donde pasada la urgencia inicial, la dinámica escolar retoma su ritmo inicial e incluso se vuelve anquilosada. Una de las principales estrategias que se pueden impulsar para afrontar estos retos, a partir de un liderazgo orientado a la justicia social, es la articulación entre las demandas de redistribución y reconocimiento. 
Como lo ha expresado Fraser (2008), tanto las políticas de redistribución, como las de reconocimiento, identifican distintas fuentes de injusticia. La primera, asocia la injusticia a una falta en las relaciones de producción y aspira a equilibrar esas desigualdades, que relacionan a las clases enfrentadas en función de la posición que ocupan (explotadores/explotados) más no de su identidad per se. La segunda política, de reconocimiento, asocia la injusticia a una política identitaria y de representación que establece relaciones de poder y subordinación. En este caso, la injusticia sería inherente a los grupos identitarios en confrontación.

Estas diferentes fuentes de injusticia se sustentan en paradigmas populares opuestos, que a su vez están asociados a movimientos sociales específicos, en donde cada uno concibe que la otra reivindicación opera en detrimento suyo. La autora propone que esta aparente exclusión mutua de ambas demandas se puede superar a través de su intersección. En donde las injusticias de carácter económico-estructural se intersectan con las identitarias (género, etnia, orientación sexual) y viceversa.

Esto es factible a través de lo que Fraser (2008) denomina "concepción bidimensional de la justicia" (p. 84), o en términos de Santos (2007) la "teoría de la traducción” (p. 202), en donde ambas demandas entablan nexos comunes en el momento en que trascienden su localismo, sin por ello perder su especificidad. En ese sentido la aportación de Santos es el ejercicio estratégico de las reivindicaciones de igualdad y diferencia, lo que mantiene un "equilibrio tenso y dinámico" (p. 203) entre ambas, en aras a proyectar las luchas contrahegemónicas.

Este equilibrio tenso y dinámico presenta retos particulares para los líderes escolares, ya que al ser escasos sus recursos requieren priorizar necesidades, lo cual les demanda una capacidad de armonizar las necesidades detectadas en sus comunidades escolares (DeMatthews, 2014). Un escenario frecuente de estos dilemas sería el reto de construir un proyecto de escuela inclusiva y diversa, a la que concurran tanto alumnos regulares como aquéllos con capacidades diferentes. Siguiendo las premisas del ODS 4, una educación "inclusiva, equitativa y de calidad, que promueva oportunidades de aprendizaje durante toda la vida para todos" (UNESCO, 2017, p. 18), dicho proyecto sería un acierto. Sin embargo, enfrenta retos de mediación sumamente complejos, que requieren no sólo atender a las demandas de los actores implicados sino además ser capaz de sostenerse en el tiempo.

Ante dilemas espinosos como este, Sugrue (2015) subraya la capacidad de adaptación ante dilemas complejos como un componente clave del liderazgo. Dicha adaptación involucra en primer lugar la asimilación del director a su comunidad escolar. El balance entre navegar por los senderos de sus predecesores y negociar con su colectivo las condiciones que incidirán en el proyecto que encabezará es lo que el autor denomina "navegociación" (p. 22). Sugrue establece esta ruta a partir de su crítica al perfil insostenible del líder trágico-heróico, ese súper individuo que sacrifica su vida y su salud por su trabajo. Junto al heroísmo trágico, el imaginario que se construye sobre el docente, que va de la idealización romántica a la burda burocratización, contribuye al desgaste y la desmotivación que asedian a la profesión (Gimeno, 2008).

Ante este panorama, la importancia de saberse en un estado de crisis permanente surge como un imperativo ante los retos que un contexto cambiante impone a la labor del profesorado (Gimeno, 2008). No obstante, la tendencia a la labor en solitario que el docente ejerce conlleva el riesgo no solo de aislarlo profesional y socialmente sino incluso 
de reforzar el modelo del líder trágico-heroico. De ahí la importancia que Sugrue (2015, p. 12) otorga a involucrar a la comunidad escolar en la toma de decisiones, a fin de superar el "liderazgo solitario", y la que Torres (2009, p. 46) atribuye a abrir "espacios de reflexión" para consolidar la profesionalización de la docencia. En ese marco, las prácticas de liderazgo distribuido o compartido adquieren factibilidad dentro del paradigma de la sostenibilidad. Derivado de lo anterior, surgen algunas habilidades básicas que el colectivo docente puede desarrollar para mantener encendido el fuego de la justicia social, sin sucumbir en el intento. Principalmente cabe señalar la capacidad escolar y el liderazgo distribuido de DeMatthews, la navegociación de Sugrue y las estrategias de respaldo de Theoharis, todas ellas convergen en la importancia de desarrollar una estructura comunicativa fluida y horizontal que el director es capaz de ejercer y hacer que su equipo asimile y aprehenda. Esta no es una tarea fácil, pues requiere principalmente de amplia capacidad de convocatoria.

Un ejemplo ilustrativo es el que Apple (2017) expone a partir de su propia experiencia, cuando, como un docente que busca ejercer una mediación pedagógica crítica y dialógica, relata el ejercicio que realizó para cuestionar la narrativa de los libros de texto, en particular de la asignatura "Estudio de la Comunidad", en donde identificó cómo se encubrían las tramas de discriminación y racismo, en relación al contexto de una localidad marginada enclavada en el norte de los Estados Unidos. Para ensayar una práctica disruptiva y desapegada de la norma oficial legitimada en los libros de texto, llevó a sus estudiantes al museo local. Hallaron que en dicho pueblo hasta hace poco había células activas del Ku Klux Klan, a lo cual se agregaba el historial de intolerancia y supremacismo blanco que amedrentaba a las minorías en la ciudad.

A partir de esta experiencia, los estudiantes elaboraron un periódico escolar, en el que cuestionaban el discurso de la historiografía nacional que invisibiliza las prácticas racistas que se manifiestan en el norte de los Estados Unidos, tradicionalmente asociado con el antiesclavismo. Al comenzar a circular en la comunidad, el periódico levantó una fuerte polémica entre los sectores conservadores del pueblo e incluso hubo intentos de despedir a los maestros. Sin embargo, todo el cuerpo docente junto con el director y otros miembros de la comunidad, se negaron a permitir que dicho núcleo conservador obstaculizara su ejercicio de construir, críticamente, una educación más democrática.

El caso que Apple describe ofrece algunas pistas para ubicar los aportes que la Educación para el Desarrollo Sostenible puede ofrecer a un colectivo docente orientado a la justicia social desde el liderazgo sostenible. Desde la perspectiva crítica ejercida por Apple, se pueden establecer algunos paralelismos con los aprendizajes relacionados con el ODS 10, "Reducción de las desigualdades" (UNESCO, 2017, p. 30). A nivel cognitivo esto se expresó en la concientización de los procesos que promueven conductas y decisiones discriminatorias. A contracorriente del discurso historiográfico sobre la lucha por los derechos civiles, en el norte de los Estados Unidos se visibilizaron ciertas expresiones de discriminación a la comunidad afroamericana. A nivel socioemocional, se desarrollaron capacidades empáticas y de solidaridad hacia quienes padecen discriminación, y a nivel conductual, se desarrollaron y planificaron estrategias (el periódico escolar) orientadas a reducir las desigualdades o en este caso a denunciar la persistencia de la discriminación.

Tanto la perspectiva crítica como aquélla orientada a la sostenibilidad enfrentan retos que requieren de un liderazgo ético y de la intervención deliberada de Turhana (2010), aunque la primera exige un proceso de concientización previo e incluso de un posicionamiento 
político e ideológico. Por lo tanto, cuando dicho proceso es incipiente, la sostenibilidad puede contribuir a acercar a los líderes escolares a abordar las problemáticas que el enfoque crítico tiene como parte de sus ejes, en este caso la discriminación, que se enmarca en el objetivo más general de la reducción de las desigualdades. Pero el enfoque crítico es uno de varios que pueden fomentarse desde el eje de la sostenibilidad y que no necesariamente se encuentran plenamente asumidos en las problemáticas que rodean al entorno escolar. A través de los objetivos de aprendizaje que invitan a la reflexión sobre los 17 ODS, el director como líder de su comunidad educativa tiene al alcance una serie de estrategias para abordar las problemáticas que atañen a los retos de su entorno.

Por otro lado, la experiencia reseñada por Apple resulta ilustrativa del bosquejo del líder para la justicia social. Se observa la resistencia enfocada en los aprendizajes de la que habla Theoharis, pues hubo un cuestionamiento a la versión de la historia que se legitima en el currículo oficial. También aparece una articulación de las demandas de redistribución y reconocimiento que señalan Fraser y Santos, en tanto que convergieron el racismo y la desigualdad económica asociada a ella en el ejercicio deconstructivo de la narrativa oficial que los estudiantes elaboraron en el periódico escolar. Asimismo, dicha experiencia resulta cercana a la posición "radical democrática" de Freire (2009, p. 261), mediante la cual se ejerce un papel directivo, sin caer en el autoritarismo ni en la permisividad. Dicha práctica se enmarca en su modelo de educador liberador, porque asume su responsabilidad como líder para dirigir un estudio de manera rigurosa y reflexiva.

Finalmente, aparece la capacidad escolar y el liderazgo distribuido, los cuales se manifestaron en la sólida cohesión lograda entre el cuerpo docente y el director junto con la propia comunidad, pues entre todos cerraron filas ante la reacción que amenazó con terminar esta experiencia crítica y orientada a la justicia social. Por lo tanto, las diversas estrategias que se pueden ejercer desde el liderazgo sostenible y orientado a la justicia social pueden resultar efectivas y trascendentales cuando se logra diseminar, entre los agentes que intervienen en la escuela, un mismo sentido de responsabilidad moral por cuestionar las estructuras jerárquicas que legitiman las injusticias y en ese proceso, constituirse como agentes para la justicia social.

\section{Conclusiones}

El planteamiento de la justicia social como un espectro delimitado por tres aristas permite mostrar cómo conviven principios claves de dichos referentes teóricos en la elaboración de una agenda pública para la justicia social. A su vez, estos postulados pueden orientar una agenda programática, como la del desarrollo sostenible, que porta una noción de lo justo que se asume deseable y consensual. Las demandas de redistribución y reconocimiento aparecen junto con la construcción de una identidad relacional, que es lo que da sentido a la construcción del bien que se elabora en el registro individual del liberalismo, pero que apunta a un referente colectivo, según la justicia social crítica. Desde este marco, situamos algunos de los principales aportes del liderazgo escolar para la justicia social. En dicha articulación un concepto clave fue el "agente de justicia" de Pereira, el cual se entrelaza con el líder activista de Turhana.

A partir de este eslabonamiento se colocaron algunas de las propuestas teóricas y programáticas para habilitar el liderazgo para la justicia social. Estas propuestas se caracterizan por la responsabilidad moral que el líder asume para con su comunidad y el 
potencial que visualiza para ejercer acciones dirigidas a subvertir el orden que legitima las injusticias sociales. El papel que juega la escuela en ese sentido es clave, pues es una institución en donde convergen transversalmente las diferentes manifestaciones de injusticia, las relacionadas con demandas de redistribución y aquéllas asociadas con las demandas de reconocimiento.

Como se vio anteriormente, ambas demandas no son necesariamente antagónicas, sino que su articulación es posible y necesaria pues reflejan la intersección de diferentes dimensiones de injusticias. El reto consiste en cómo armonizarlas, como bien lo expuso DeMatthews. Un posible itinerario aparece delineado en la propuesta de "navegociación" de Sugrue. La capacidad de gestionar las problemáticas que atraviesan al espacio escolar desde su propia dinámica y la que proviene de su entorno, permite visualizar los puntos de encuentro entre demandas que parecen de diferente cuño. Esta estrategia se acompaña necesariamente de la capacidad escolar y el liderazgo distribuido anteriormente señalados. La capacidad de armonizar ambas estrategias reside en un equipo articulado, que asume la responsabilidad moral de enfrentar las injusticias desde el mismo espacio escolar, teniendo el potencial de influir en su entorno más amplio, rasgos propios del liderazgo sostenible.

La EDS por su parte ofrece un marco de referencia para el ejercicio de un liderazgo orientado a la justicia social. El largo proceso de reflexión en torno a la sostenibilidad y su supuesto del desarrollo de capacidades para la satisfacción de necesidades, postulado compartido con las doctrinas morales comprehensivas, son elaboraciones enmarcadas en la discusión por la justicia social, que se llegan a concretar en acuerdos y objetivos que involucran la participación de diversos actores.

Este panorama exige en particular del director como líder escolar desarrollar la "capacidad escolar" (DeMatthews, 2014) necesaria para impulsar los cambios que contribuyan a construir un entorno más justo. El posible traslape de intereses entre actores, la necesidad de mediar entre las demandas de redistribución y reconocimiento, la identificación de prioridades en medio de recursos limitados, son retos que demandan un liderazgo que eche mano tanto de las estrategias proactivas como las de respaldo (Theoharis, 2007), en aras a generar las condiciones que acerquen al colectivo escolar, a las metas que contribuyan a construir un entorno más justo y sostenible.

\section{Referencias}

Apple, M. (2017). The struggle for democracy in critical education. e-Curriculum. Revista del Programa de Posgraduacao en Educacao, 15(4), 894-923. https:/doi.org/10.23925/1809-3876.2017v15i4p894-926

Bogotch, I. y Reyes-Guerra, D. (2014). Leadership for social justice: Social justice pedagogies. Revista Internacional de Educación para la Justicia Social, 3(2), 33-58.

Bolívar, A. (2012). Justicia social y equidad escolar: Una revisión actual. Revista Internacional de Educación para la Justicia Social, 1(1), 9-45.

Bórquez, B. y Lopicich, B. (2017). La dimensión bioética de los objetivos de desarrollo sostenible (ODS). Revista de Bioética y Derecho Perspectivas Bioéticas, 41, 121-139.

Brown, K. (2014). Principal leadership in "beating the odds" schools... advocates for social justice and equity. Revista Internacional de Educación para la Justicia Social, 3(2), 59-83. 
DeMatthews, D. (2014). Dimensions of social justice leadership: A critical review of actions, challenges, dilemmas, and opportunities for the inclusion of students with disabilities in U.S. schools. Revista Internacional de Educación para la Justicia Social, 3(2), 107-122.

De Vita, A. (2014). Critical theory and social justice. Brazilian Political Science Review, 8(1), 109126.

Foladori, G. (2006). La insostenibilidad social del desarrollo sostenible. Portularia, 6(2), 7-20.

Fraser, N. (2008). La justicia social en la era de la política de identidad: Redistribución, reconocimiento y participación. Revista de Trabajo Nueva Época, 4(6), 83-102.

Freire, P. y Shor, I. (2014). Miedo y osadía. La cotidianidad del docente que se arriesga a practicar una pedagogía transformadora. Buenos Aires: Siglo XXI.

Gimeno, J. (2008). ¿De dónde viene la crisis de la profesión docente? Cadernos de Edcuacao, 30, 7988.

Giraldo-Piedrahita, F. (2015). Expresión de tres perspectivas de la justicia social en la organización de los sistemas de salud. Revista Gerencia y Políticas de Salud, 14(29), 26-40.

https://doi.org/10.11144/Javeriana.rgyps 14-29.etpj

González, M. (2014). Liderazgo para la justicia social en organizaciones educativas. Revista Internacional de Educación para la Justicia Social, 3(2), 85-106.

Hargreaves, A. y Fink, D. (2008). El liderazgo sostenible. Siete principios para el liderazgo en centros educativos innovadores. Madrid: Morata.

Heredia, N. y Martínez, J. (2014). Justicia educativa: Nociones, teorías y reflexiones para el desarrollo de prácticas escolares justas. Educación y Ciencia, 42(3), 21-33.

Honneth, A. (1997). La lucha por el reconocimiento. Por una gramática moral de los conflictos sociales. Barcelona: Crítica Grijalbo Mondadori.

Jean-Marie, G., Normore, H. y Brooks, J. (2009). Leadership for social justice: Preparing $21 \mathrm{st}$ century school leaders for a new social order. Journal of Research on Leadership Education, 4(1), 1-30. https://doi.org/10.1177/194277510900400102

Murga-Menoyo M. A. (2018). La formación de la ciudadanía en el marco de la agenda 2030 y la justicia ambiental. Revista Internacional de Educación para la Justicia Social, 7(1), 37-52. https://doi.org/10.15366/riejs2018.7.1.002

Murillo, F. J. y Hernández-Castilla, R. (2011). Hacia un concepto de justicia social. REICE. Revista Iberoamericana sobre Calidad, Eficacia y Cambio en Educación, 9(4), 7-23.

Murillo, F., Hernández-Castilla, R., Hidalgo, N. y Martínez-Garrido, C. (2014). Elaboración y evaluación psicométrica de la escala de actitudes hacia la justica social en educación (EAJSE). Revista Internacional de Educación para la Justicia Social, 3(2), 215-233.

Nussbaum, M. (2012). Las fronteras de la justicia. Consideraciones sobre la exclusión. Barcelona: Paidós.

Peñaranda F. (2015). Salud pública, justicia social e investigación cualitativa: Hacia una investigación por principios. Revista Facultad Nacional de Salud Pública, 33(1), 103-111. https://doi.org/10.17533/udea.rfnsp.v33n3a04

Pereira, G. (2016). Más allá del liberalismo: El enfoque de capacidades y la justicia social crítica. Tópicos, Revista de Filosofía, 51, 83-111. https://doi.org/10.21555/top.voio.759

Rauber, I. (2012). Revoluciones desde abajo: gobiernos populares y cambio social en Latinoamérica. Buenos Aires: Ediciones Continente.

Rawls, J. (1999). A theory of justice. Oxford: Oxford University Press. 
Santamaría, I. y Stuardo, M. (2018). Una mirada a prácticas docentes desde un marco de justicia social. Revista Internacional de Educación para la Justicia Social, 7(1), 177-196. https://doi.org/10.15366/riejs2018.7.1.009

Santos, B. (2007). Conocer desde el sur. Para una cultura política emancipadora. Buenos Aires: CLACSO.

Sanz-Ponce, J. R. y Serrano-Sarmiento, A. (2016). El desarrollo de capacidades en la educación. Una cuestión de justicia social. Sinéctica, Revista Electrónica de Educación, 46, 1-16.

Sen, A. (2009). The idea of justice. Cambridge, MA: Belknap Press.

Sugrue, C. (2015). Unmasking school leadership. A longitudinal life history of school leaders. Dordrecht: Springer. https://doi.org/10.1007/978-94-0 17-9433-6

Theoharis, G. (2007). Social justice educational leaders and resistance: Toward a theory of social justice leadership. Educational Administration Quarterly, 43(2), 221-258. https://doi.org/10.1177/0013161X06293717

Torres, J. (2009). La desmotivación del profesorado. Madrid: Morata.

Turhana, M. (2010). Social justice leadership: Implications for roles and responsibilities of school administrators. Procedia Social and Behavioral Sciences, 9, 1357-1361. https://doi.org/10.1016/j.sbspro.2010.12.334

UNESCO. (2017) Educación para los objetivos de desarrollo sostenible. París: UNESCO.

Vergara Tamayo, C. A. y Ortiz Motta D. C. (2016). Desarrollo sostenible: Enfoques desde las ciencias económicas. Apuntes del CENES, 35(62), 15-52.

https://doi.org/10.19053/22565779.4240

Yilmaz, E. (2016). A methodological dialogue on justice. Nordic Journal of Political Economy, 41(1), $1-19$.

\section{Breve CV de los autores}

\section{Maricela Guzmán Cáceres}

Profesora Investigadora de Tiempo Completo en la Escuela de Ciencias de la Comunidad de la Universidad Autónoma de Coahuila. Socióloga, Maestra en Investigación Educativa, Maestra en Ciencias Sociales y Doctora en Planeación y Liderazgo Educativo, realizó un Posdoctorado en la Universidad Nacional Autónoma de México. Ha sido directora y colaboradora en siete proyectos de investigación financiados por Conacyt y su trabajo ha sido publicado en libros, artículos científicos y Congresos en México y el extranjero. Es líder del Cuerpo Académico "Sociología de las Organizaciones, Intervención Social y Desarrollo Humano”, en el que desarrolla una línea de investigación sobre liderazgo educativo para la justicia social. ORCID ID: https://orcid.org/O000-0003-1180-842X. Email: mari68mx@yahoo.com.mx

\section{Leonardo Oliver Ortiz Flores}

Licenciado y Maestro en Estudios Latinoamericanos por la Universidad Nacional Autónoma de México (UNAM), con énfasis en temas de educación y políticas públicas. Ha sido becario del programa Alternativas Pedagógicas y Prospectiva Educativa en América Latina (APPEAL) de la UNAM y participó en dos proyectos de investigación financiados por el Instituto de Investigaciones para el Desarrollo de la Educación (INIDE) de la Universidad Iberoamericana. Asimismo, ha incursionado en la iniciativa privada en el 
M. Guzmán Cáceres y L. O. Ortiz Flores

campo de la comunicación y estrategia política. Actualmente se desempeña como consultor externo de la Oficina de la UNESCO en la Ciudad de México. ORCID ID: https://orcid.org/0000-0002-8998-8216. Email: oliver.ortiz@hotmail.com 